\title{
Radiopharmaceuticals in cardiology
}

Renata Mikołajczak, Piotr Garnuszek

National Centre for Nuclear Research, Radioisotope Centre POLATOM, Otwock, Poland

[Received 16 I 2012; Accepted 31 I 2012]

\begin{abstract}
Myocardial perfusion studies are among the most often performed investigations in Nuclear Medicine. However, the development of radiopharmaceuticals for cardiology is an emerging discipline and several other radiotracers have been proven to be useful. Although the myocardial perfusion studies have a wellestablished role in the management of cardiac disorders, still a number of radiopharmaceuticals are under development for a variety of specific cardiac indications and their eventual clinical role remains to be seen. The paper provides a short overview of currently used radiopharmaceuticals and potential molecular imaging radiotracers applicable in cardiology.

Key words: nuclear medicine, nuclear cardiology, cardiac imaging radiopharmaceuticals, status and trends
\end{abstract}

Nuclear Med Rev 2012; 15, 1: 39-45

\section{Introduction}

Myocardial perfusion studies are among the most often performed investigations in Nuclear Medicine. That high number of studies is facilitated by the availability of suitable tracers radiolabelled with ${ }^{99 m} \mathrm{Tc}$. Hence, the technetium agents were used for more than $90 \%$ of the 8 million cardiac imaging studies in the US in 2006 [1] out of a total of over 20 million nuclear medicine procedures. The number of cardiac imaging studies performed in Europe is generally lower than in US and it is varying between European countries. In Poland utilization of the nuclear cardiology procedures performed in 2008 accounted for little over 11 per cent of the total number of nuclear medicine procedures [2]. However, the development of radiopharmaceuticals for cardiology is an emerging discipline and several other radiotracers have been proved to be useful. The aim of this paper is to provide the brief

Correspondence to: Renata Mikołajczak

National Centre for Nuclear Research, Radioisotope Centre POLATOM

7 Andrzeja Soltana St., 05-400 Otwock, Poland

Tel.: +482271807 01, Fax: +48227180350

e-mail: r.mikolajczak@polatom.pl overview of the radiopharmaceuticals available today and also on the tracers which are entering the field.

\section{Myocardial perfusion}

Myocardial perfusion imaging is a well established noninvasive method of assessing coronary blood flow. It is capable of identifying regional abnormalities in coronary artery blood flow and determining their physiological relevance to myocardial function and viability. Used frequently in conjunction with either physical exercise or pharmacological stress, the myocardial perfusion imaging is useful in unmasking myocardial perfusion deficits not evident at rest [3].

Among the earliest developed radiopharmaceuticals used in cardiology there were tracers for measurement of myocardial blood flow [4]. The first radioactive tracer used to asses perfusion was potassium-43, because of its avid extraction and retention. Since the 1970's, thallium-201 ( ${ }^{201} \mathrm{TI}, \mathrm{t}_{1 / 2}=73 \mathrm{~h}$ ) has been used extensively as myocardial perfusion agent for assessing myocardial viability [5]. The uptake of these tracers occurs predominantly through the $\mathrm{Na}^{+} / \mathrm{K}^{+}$channel. For ${ }^{201} \mathrm{TI}$, the rapid myocardial extraction depends on perfusion, whereas the myocardial retention/redistribution reflects myocardial viability. In the 1980's, lipophilic technetium-99m complexes were demonstrated as good myocardial perfusion agents [6]. Currently, sestamibi [7] and tetrofosmin [8] are approved agents by FDA, sestamibi is also approved in EU. Recently a number of generic sestamibi kits have been granted marketing authorization. The most frequently used SPECT and PET tracers for assessing myocardial blood flow are presented in Table 1. Their more detailed characteristics is given below.

\section{SPECT perfusion tracers}

\section{Thallous $\left({ }^{201} \mathrm{TI}\right)$ chloride injection}

USP [10], Ph. Eur. [11] (monograph 0571). ${ }^{201} \mathrm{Tl}$ is a cyclotron produced radionuclide with the half-life of 73 hours. For many years, planar imaging and SPECT with thallium-201 chloride constituted the only scintigraphic technique available for detecting coronary artery disease and assessing prognosis in patients undergoing stress perfusion imaging [12]. The chemical properties of this monovalent cation result that it acts similarly to potassium and is taken into viable cardiac myocytes. It distributes in cardiac tissue roughly in proportion to regional blood flow. In practice, it is injected when the patient is at peak exercise or shortly after the pharmacologic stress agent is administered. Defects on the initial image can represent regional ischemia or nonviable myocardium. As the cardiac stress is discontinued, the thallium-201 redistributes and 
Table 1. Comparison of the main blood flow tracers. Table derived from [9]

\begin{tabular}{|c|c|c|c|c|}
\hline Tracer & Physical half-life & $\begin{array}{l}\text { Myocardial } \\
\text { extraction (\%)* }\end{array}$ & $\begin{array}{l}\text { Clearance } \\
\text { half-life }\end{array}$ & Viability \\
\hline \multicolumn{5}{|l|}{ SPECT } \\
\hline Thallium-201 & $73 \mathrm{~h}$ & 85 & Slow & +++ \\
\hline${ }^{99 m} \mathrm{Tc}$-sestamibi & $6 \mathrm{~h}$ & 65 & Very slow & ++ \\
\hline${ }^{99 \mathrm{~m}} \mathrm{Tc}$-tetrofosmin & $6 \mathrm{~h}$ & 60 & Very slow & ++ \\
\hline \multicolumn{5}{|l|}{ PET } \\
\hline Rubidium-82 & $76 \mathrm{~s}$ & 65 & Slow & ++ \\
\hline${ }^{13} \mathrm{~N}$-ammonia & $10 \mathrm{~min}$ & 80 & Very slow & + \\
\hline${ }^{15} \mathrm{O}$-water & $2 \min$ & 100 & Fast & ++ \\
\hline
\end{tabular}

*Extraction is flow dependent; values given represent estimates at resting flow rates.

fills in areas that were underperfused due to ischemia (reversible defect). Regions of the heart that have been irreversibly damaged by previous myocardial infarction do not demonstrate resolution of the defect on the delayed image (fixed defect). In this way, the test can discriminate the regions of inducible ischemia at risk for future myocardial infarction and areas that have been already irreversibly damaged by prior myocardial infarction. Thallium-201 has several virtues as a myocardial perfusion agent [13]. It is characterized by regional blood clearance half-time of $<30 \mathrm{~s}$ and a first pass ex-

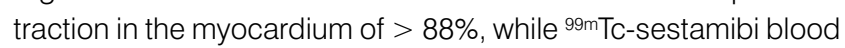
clearance half-time is $>1 \mathrm{~min}$ and a first pass extraction in the myocardium is $50 \%$ to $60 \%$. These biological characteristics of thallium provide higher contrast between regions of normal perfusion and zones of ischemia, even on planar myocardial perfusion studies (see Table 1). Some physical and biological characteristics of thallium, however, are not so favorable. The electron capture decay of ${ }^{201} \mathrm{TI}$ produces $88 \mathrm{X}$-ray photons at 70 to $80 \mathrm{keV}$ and approximately 12 gamma photons at 135 and $167 \mathrm{keV}$ for each disintegration. In addition to the low energy of the predominant photon, the physical half-life of $73 \mathrm{~h}$ and biological half-life of approximately 10 days $(240 \mathrm{~h}$ ) results in a relatively long effective half-life of approximately $56 \mathrm{~h}$. In addition to myocardium, skeletal muscle and liver, the tracer also localizes in the testes and kidneys, producing an affective dose equivalent to $34.5 \mathrm{mSv} / 150 \mathrm{MBq}$. Due to relatively high absorbed dose the administered radioactivity of ${ }^{201} \mathrm{Tl}$ is usually limited to well below $150 \mathrm{MBq}$, which in turn may limit the image quality.

\section{Technetium ( $\left.{ }^{99 m} \mathrm{Tc}\right)$ sestamibi injection}

USP [10], Ph. Eur. [11] (monograph 1926). ${ }^{99 m} T c-s e s t a m i b i$ (99mTC-MIBI; Fig. 1) is a cationic, lipophilic complex that consists of 1 atom of ${ }^{99 m} T_{c}$ in a $1+$ oxidation state and 6 molecules of 2-methoxyisobutylisonitrile (MIBI).

Sestamibi contains isonitrile groups that form a complex with ${ }_{99 m} \mathrm{Tc}$ after reduction with stannous ions. Since isonitriles are volatile and unstable compounds, MIBI is available in stabilized form as copper tetrafluoroborate adduct, $\left[\mathrm{Cu}(\mathrm{MIBI})_{4}\right] \mathrm{BF}_{4}$, which should be decomposed during radiolabelling carried out at elevated temperature. Lyophilized Sestamibi kits (Cardiolite, ${ }^{99 \mathrm{~m} T \mathrm{TC}-\mathrm{MIBI}}$ kit, CardioTop, Technescan Sestamibi, etc.) contain a mixture of [tetrakis(2-methoxy-2-methylpropyl-1-isocyanide)copper $(1+)$ ] tetrafluoroborate as the active substance, and excipients like:

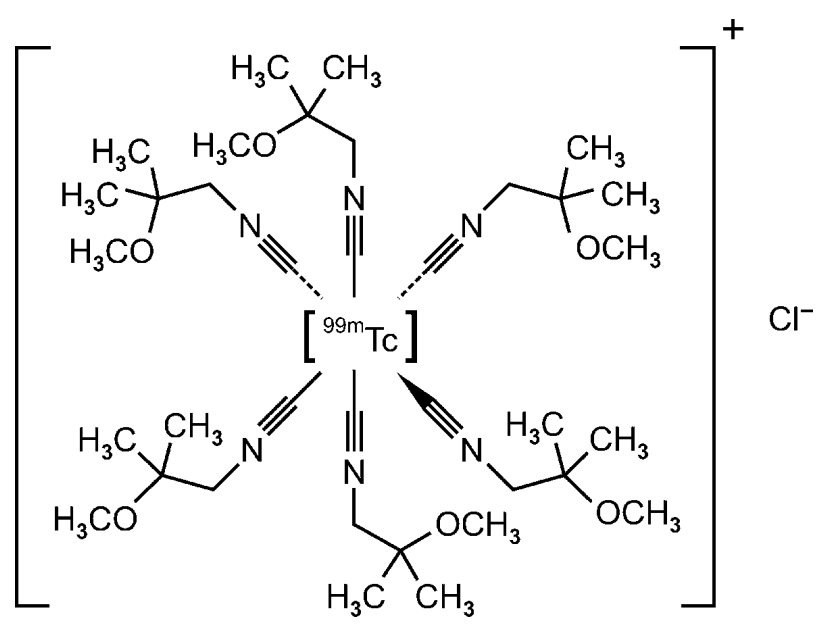

Figure 1. Structure of ${ }^{99 m}$ Tc-sestamibi ((OC-6-11)-hexakis[1(isocyano- $\kappa \mathrm{C}$ )-2-methoxy-2-methylpropane] [ ${ }^{99 \mathrm{~m} T \mathrm{~T}}$ ]technetium(I) chloride)

stannous chloride (reductant), L-cysteine hydrochloride (ancillary reductant), sodium citrate (buffering substance), and mannitol (bulking agent). Radiolabelling is carried out by adding a sufficient amount of sterile, non-pyrogenic, oxidant-free sodium

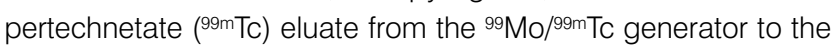
kit vial and heating the mixture in a boiling water bath for $10 \mathrm{~min}$.

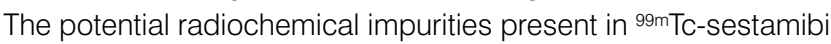
preparation that can affect image quality are: pertechnetate $\left.{ }^{99 m} \mathrm{Tc}\right)$ ion, technetium-99m in colloidal form, and ${ }^{99 m} \mathrm{Tc}$-pentamibi dimethylvinyl isonitrile ((OC-6-22)-pentakis[1-(isocyano- $\kappa$ C)-2-methoxy-2-methylpropane] [1-(isocyano- $\kappa C$ )-2-methylprop-1-ene] [99mTc]technetium $(1+))$.

The U.S. Pharmacopeia requires that a mean of not less than $90 \%$ of the total radioactivity is represented by ${ }^{99 m} \mathrm{Tc}$-sestamibi, and a mean of not more than $5 \%$ of the total radioactivity is present as ${ }^{99 m}$ Tc-pentamibi dimethylvinyl isonitrile. The quality requirements for sestamibi are also set in the European Pharmacopoeia monograph 1926 and they are stringent, i.e.: technetium-99m sestamibi: minimum 94 per cent of the total radioactivity; sum of pertechnetate ${ }^{99 \mathrm{~m} T c)}$ ion and other polar impurities and technetium-99m in colloidal form: maximum 5 per cent of the total radioactivity; ${ }^{99 m}$ Tc-pentamibi dimethylvinyl isonitrile: not more than 3 per cent of the total radioactivity. 
${ }^{99 m}$ TC-sestamibi is used as a substitute for ${ }^{201}$ TI for myocardial perfusion imaging. It is used primarily for detection of myocardial perfusion abnormalities, particularly for detection of myocardial ischemia and infarcts. This radiopharmaceutical is also useful for the assessment of myocardial function using the first-pass radionuclide ventriculographic technique (FPRV). ${ }^{99 m} \mathrm{Tc}-$ sestamibi is taken up by the cells of the myocardium in passive diffusion and then appears in the cytosol and is localized in the mitochondria. The uptake is proportional to the myocardial perfusion, and the washout is rather slow (excluding considerable redistribution). At stress, more than $3 \%$ of the injected dose is accumulated in the myocardium, while the nonbound part is eliminated via the hepatobiliary route. Technetium-99m sestamibi acts as a calcium analog when taken up by the heart. Once taken by myocardial myocytes, redistribution does not occur as it does for the thallium-201. Consequently, when performing a technetium-99m scan, a second injection is given at the time of the delayed image [14].

\section{Technetium ( $\left.{ }^{99 m} \mathrm{Tc}\right)$ tetrofosmin injection}

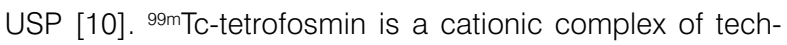
netium-99m at the oxidation state $5+$ and two molecules of tetrofosmin ([6,9-bis(2-ethoxyethyl)-3, 12-dioxa-6,9-diphospha-tetradecane] (Fig. 2). The chemical formula of the ${ }^{99 m} \mathrm{mc}-\mathrm{complex}$ is [ ${ }^{99 m} \mathrm{Tc}$ (tetrofosmin) $\left.{ }_{2} \mathrm{O}_{2}\right]^{+}$with a charge of $1+$

${ }^{99 m}$ Tc-tetrofosmin is a diagnostic radiopharmaceutical used in nuclear medicine cardiac imaging [8]. It is commercially available as lyophilized kit under the brand name Myoview (GE Healthcare). The Myoview kit contains a lyophilised mixture of $0.23 \mathrm{mg}$ of tetrofosmin as the active substance and excipients: stannous chloride dehydrate, disodium sulfosalicylate, sodium D-gluconate, and sodium hydrogen carbonate. Radiolabelling is carried out by adding sodium pertechnetate ( ${ }^{99 \mathrm{~m} T c)}$ eluate from the ${ }^{99} \mathrm{Mo} /{ }^{99 m} \mathrm{Tc}$ generator to the kit vial and incubating the mixture

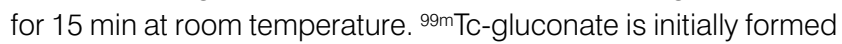
with reduced ${ }^{99 \mathrm{~m} T c}$, which is obtained by stannous ion reduction, and then ligand exchange between ${ }^{99 m}$ Tc-gluconate and the tetrofosmin group gives ${ }^{99 m} \mathrm{Tc}$-tetrofosmin. The radiochemical purity of ${ }^{99 m}$ Tc-tetrofosmin should not be less than $90 \%$ of the total radioactivity [15].

Uptake of ${ }^{99 \mathrm{~m} T c}$-tetrofosmin in the myocardium and in tu-

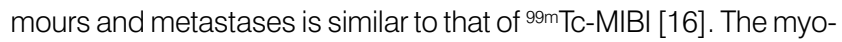

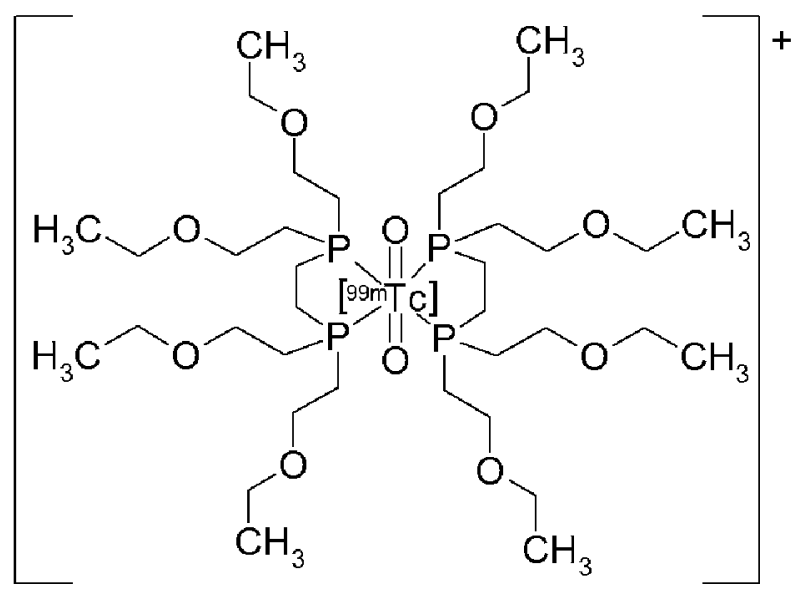

Figure 2. Structure of ${ }^{99 m} \mathrm{Tc}$-tetrofosmin. cardial uptake of ${ }^{99 m}$ Tc-tetrofosmin appears to occur by a passive diffusion process (no redistribution). Intravenously administered, it is rapidly taken up by myocardial tissue and reaches its maximum level in approximately 5 minutes. $66 \%$ of the total injected dose is excreted within 48 hours after injection ( $40 \%$ urine, $26 \%$ feces). $99 \mathrm{mTc}$-tetrofosmin is indicated for use in scintigraphic imaging of the myocardium under stress and rest conditions. It is used to determine areas of reversible ischemia and infarcted tissue in the heart. It is also indicated to detect changes in perfusion induced by pharmacologic stress (adenosine) in patients with coronary artery

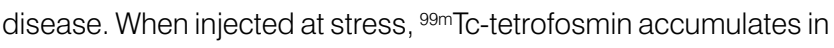
viable myocardial tissue in relation to myocardial blood flow; thus, ischemic areas (e.g., those supplied by stenotic vessels) are detectable as areas of less accumulation. Its third indication is to assess left ventricular function (ejection fraction) in patients thought to have heart disease.

\section{PET perfusion tracers}

Several positron-emitting radionuclides are also utilized to obtain tomographic images of regional myocardial perfusion (see Table 1), metabolism and the receptor density [17]. Four different approaches have been utilized for assessment of myocardial viability: (1) perfusion-FDG metabolism imaging, (2) determination of oxidative metabolism with ${ }^{11} \mathrm{C}$-acetate, (3) uptake and retention of ${ }^{82} \mathrm{Rb}$ and (4) the water perfusable tissue index [5]. These PET tracers not only allow for the diagnosis of coronary artery disease with a high degree of sensitivity and specificity, but using mathematical models also allow quantitative assessment of myocardial perfusion.

\section{Rubidium ( $\left.{ }^{82} R b\right)$ chloride injection}

USP [10]. Rubidium-82 chloride has been introduced as tracer for myocardial imaging in consequence of searching for positron-emitting analogue of ${ }^{201} \mathrm{TI}$ with improved physical characteristics. ${ }^{82} \mathrm{Rb}$ has a half-life of $76 \mathrm{~s}$ and maximum $\beta^{+}$ energy of 3.3 MeV. It is obtained by decay of parent radionuclide ${ }^{82} \mathrm{Sr}$ from a generator system with hydrous stannic oxide column. Strontium-82 decays to ${ }^{82} \mathrm{Rb}$ with a half-life of 25 days (600 hrs), hence the useful life of a generator is about 1 month. Because of the short half-life of the daughter radionuclide, the generator can be eluted at 10 min intervals with high yield. The generator is eluted with saline and eluate is infused directly to the patient as ${ }^{82} \mathrm{Rb}$ chloride in saline. Today the ${ }^{82} \mathrm{Sr} /{ }^{82} \mathrm{Rb}$ generators are offered by Bracco Diagnostic Inc (US) as CardioGen-82 (Rubidium $\mathrm{Rb} 82$ Generator) [18]. The design and validation of an in-house generator has been also published [19].

Gould et al. [20] showed that ${ }^{82} \mathrm{Rb}$ is a short-lived tracer useful for myocardial perfusion imaging. ${ }^{82} \mathrm{Rb}$ is a cation, with an intracellular uptake across the cellular membrane that reflects active transport. It behaves as an analogue of potassium and is taken up into the heart actively by $\mathrm{Na}^{+} / \mathrm{K}^{+}$ATPase pump. It is rapidly cleared from the blood and taken up to a variable degree by all tissues and organs except brain. The short half-life of ${ }^{82} \mathrm{Rb}$ permits the entire rest/stress protocol to be completed within 45 minutes, which is very convenient for the patient. ${ }^{82} \mathrm{Rb}$ has favorable physiologic and physical properties, however it is a difficult tracer to image. It emits an unusually high-energy positron, which can travel a con- 
siderable distance in tissue before annihilating, thereby affecting global image quality [21].

\section{Ammonia $\left({ }^{13} \mathrm{~N}\right)$ injection}

USP [10], Ph. Eur. [11] (monograph 1492). ${ }^{13} \mathrm{~N}$ has a half-life of 10 minutes and maximum $\beta^{+}$energy $1.2 \mathrm{MeV}$ (must be obtained from an on-site cyclotron). It is prepared by proton irradiation of water target in cyclotron followed by reduction, distillation and trapping in a slightly acidic solution. Ammonia equilibrates with ammonium ion in the blood stream. It is the neutral ammonia species, which diffuses across biological membranes into cells and is enzymatically converted into glutamine. First pass extraction is $80 \%$ at normal flow but falls off at high flow rates. It is rapidly cleared from circulation and extracted by liver (15\%), lungs, myocardium (2-4\%), brain, kidney and bladder. Initial uptake in the lungs clears rapidly allowing visualization of the heart. A complete rest/stress protocol requires about 2 hours to allow for decay of ${ }^{13} \mathrm{~N}$ between studies. Using ${ }^{13} \mathrm{~N}$-ammonia the absolute quantification of myocardial perfusion can be performed [17].

\section{Water $\left({ }^{15} \mathrm{O}\right)$ injection}

USP [10], Ph. Eur. [11] (monograph 1582). ${ }^{15} \mathrm{O}$-water is widely used for measurement of regional cerebral perfusion, but can also be used in the heart. O-15 has a half-life of 2 minutes and maximum $\beta^{+}$energy 1.7 MeV (must be obtained from the on-site cyclotron, formed in the reaction of molecular oxygen with small amount of hydrogen). It diffuses freely across membranes and enters total body water space. Delivery of ${ }^{15} \mathrm{O}$-water to myocardial (and other) cells is efficient but rapid washout occurs, which necessitates dynamic imaging or subtraction of blood pool activity. The short half-life allows a conveniently short rest/stress imaging protocol but can result in poor counting statistics. Absolute quantification can be performed [17].

\section{Myocardial oxygen consumption}

\section{Sodium acetate $\left(\left[1^{11} \mathrm{C}\right]\right)$ injection}

USP [10], Ph. Eur. [11] (monograph 1920). ${ }^{11} \mathrm{C}$-acetate is a tracer of citric acid cycle and thus directly of oxidative metabolism, allowing assessing myocardial oxygen consumption and predicting viability. ${ }^{11} \mathrm{C}$ has a half-life of 20.4 min and maximum $\beta^{+}$energy $0.96 \mathrm{MeV}$. It is obtained from an on-site cyclotron by reacting ${ }^{11} \mathrm{C}$-carbon dioxide with ethyl-magnesium bromide followed by hydrolysis and purification. ${ }^{11} \mathrm{C}$-acetate is predominantly metabolized to ${ }^{11} \mathrm{C}$-carbon dioxide, which clears from the heart and is exhaled through the lungs. The efflux rate closely correlates with myocardial oxygen consumption over a wide range of flow, substrate use, and metabolic conditions. Rapidly accumulates in the heart, lungs (3.5\%), kidneys, liver (7.5\%), pancreas, spleen, stomach, bowel (9\%) and bone marrow, followed by washout from all organs though most rapidly from the heart. It is not excreted via the kidneys [17].

\section{Hypoxia}

Abnormalities in tissue oxygenation underlie many of the metabolic and contractile changes that occur in ischemic myocardium. As mentioned above, ${ }^{11} \mathrm{C}$-acetate can be used to indirectly

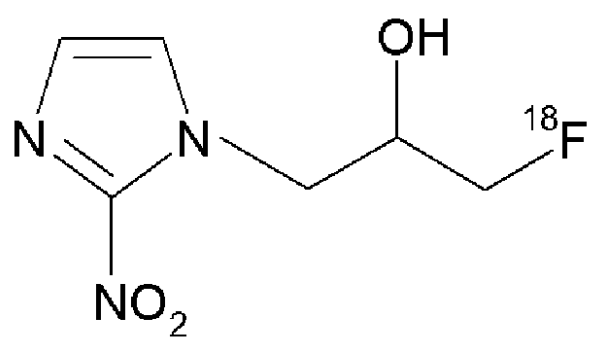

Figure 3. $\left[{ }^{18} \mathrm{~F}\right]$ Fluoromisonidazole (1-( $\left[{ }^{18} \mathrm{~F}\right]$ fluoro-3-(2-nitro-imidazol-1-yl)-propan-2-ol)

assess myocardial oxygen consumption. The use of ${ }^{15} \mathrm{O}$ is a more direct way to image myocardial oxygen consumption, but its use is quite complicated and limited to the centers with cyclotrons. Most of the tracers for imaging hypoxia that were developed so far are nitroimidazole based [22]. Nitroimidazoles are a class of lipophilic compounds with high electron affinity that have been developed as radiosensitizers of hypoxic regions in tumors [23]. These compounds readily diffuse through the cells. The nitro group can be chemically reduced to form a radical, which under normal oxygen content will react to regenerate the parent compound and diffuse out of the cell. Under hypoxic conditions, the nitro radical can interact with intracellular macromolecules and are trapped. Hypoxia tracers such as ${ }^{18} \mathrm{~F}$-fluoromisonidazole $\left({ }^{18} \mathrm{~F}-\mathrm{MISO}\right)$ and ${ }^{62 / 64} \mathrm{CU}$-ATSM are selectively trapped in hypoxic tissue by a bioreductive mechanism and result in hot spot images [24].

\section{$\left[{ }^{18}\right.$ F]Fluoromisonidazole}

$\left[{ }^{18} \mathrm{~F}\right]$ Fluoromisonidazole ( ${ }^{18} \mathrm{~F}-\mathrm{MISO}$; Fig. 3) can be easily radiolabelled by reacting 2-nitroimidazole with ${ }^{18} \mathrm{~F}$-labeled epifluorohydrin or by fluorination of O-THP protected tosylate of misonidazole followed by acidic deprotection.

\section{${ }^{64} \mathrm{Cu}-\mathrm{ATSM}$}

$\left[{ }^{64} \mathrm{Cu}(\mathrm{II})\right]$-diacetyl-bis $\left(\mathrm{N}^{4}\right.$-methylthiosemicarbazone ${ }^{64} \mathrm{Cu}-\mathrm{ATSM}$; Figure 4) is a promising agent for the imaging of hypoxic tissues. Copper-64 ( $\mathrm{T}_{1 / 2}=12.7$ hours; $\beta^{+}, 0.653 \mathrm{MeV}(17.8$ $\%) ; \beta^{-}, 0.579 \mathrm{MeV}(38.4 \%)$ ) has decay characteristics that allow for positron emission tomography (PET) imaging and targeted radiotherapy of cancer. With a high membrane permeability and redox potential, a lipophilic ${ }^{64} \mathrm{Cu}$-ATSM conjugate is preferentially taken up by hypoxic cells compared to normoxic cells [25]; the extent of retention in tissue is inversely related to the state of tissue oxygenation allowing the quantification of tissue hypoxia by<smiles>CNC1=NN2C(C)=NN3C(C)=NN(S1)[C@@H]23</smiles>

Figure 4. Structure of ${ }^{64} \mathrm{Cu}$-ATSM $\left({ }^{64} \mathrm{Cu}(\mathrm{II})\right.$-diacetyl-bis( $\left({ }^{4}\right.$-methylthiosemicarbazone) 


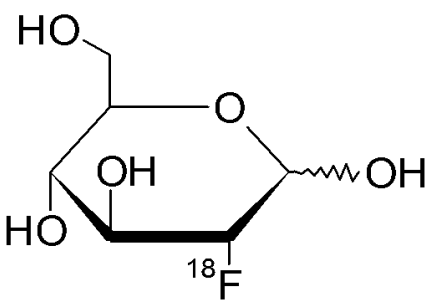

Figure 5. Structure of ${ }^{18} \mathrm{~F}-\mathrm{FDG}\left(2-\left[{ }^{18} \mathrm{~F}\right]\right.$ fluoro-2-deoxy-D-glucose)

positron emission tomography (PET). In addition, the radioactive copper moiety of this agent may deliver a selective cytotoxic dose of beta radiation to hypoxic tumor cells.

\section{Myocardial glucose metabolism}

\section{Fludeoxyglucose $\left({ }^{18} \mathrm{~F}\right)$ injection}

USP [10], Ph. Eur. [11] (monograph 1325). 2-Deoxy-2-[18F] fluoroglucose $\left({ }^{18} \mathrm{~F}-\mathrm{FDG}\right.$; Fig. 5) with the half-life of ${ }^{18} \mathrm{~F}$ of $110 \mathrm{~min}$ has been used for measuring glucose metabolism in humans. It is commonly produced by nucleophilic substitution reaction of a O-acetyl-protected mannose triflate with $\left[{ }^{18} \mathrm{~F}\right]$ fluoride (resolubilized in acetonitrile in the presence of $\mathrm{K}_{2} \mathrm{CO}_{3}$ and Kryptofix 222) followed by acid hydrolysis. The final tracer is purified using a mixed cation-anion exchange column [26].

Under physiological, fasting circumstances, the heart depends on the breakdown of long-chain fatty acids for energy needed for contraction. However, after a carbohydrate meal or with myocardial ischemia, the pattern of substrate switches to glucose. FDG is a glucose analog with a metabolic pattern different from native glucose. FDG is initially extracted at a rate different than glucose. ${ }^{18} \mathrm{~F}-\mathrm{FDG}$ is rapidly cleared from circulation with the half-time $<1 \mathrm{~min}$. Three phases can be identified with half-lives of $0.2-0.3 \mathrm{~min}, 10-13 \mathrm{~min}$ and $80-95 \mathrm{~min}$. About $30 \%$ is excreted via kidneys. Tissues of highest retention are the heart and brain. Following myocardial uptake, FDG is phosphorylated to FDG-6-phosphate and is then trapped in the myocardium because unlike phosphorylated glucose, it is a poor substrate for glycogen synthesis, the fructose phosphate shunt and glycolysis. Regional myocardial uptake of FDG therefore reflects relative distribution of regional rates of exogenous glucose utilization $[4,5]$.

\section{Radiotracers for myocardial sympathetic nerve imaging}

Regional and global abnormalities of cardiac sympathetic nervous function are involved in various clinical disorders, such as myocardial infarction, hypertrophic cardiomyopathy and congestive heart failure. The major neurotransmitter of the sympathetic nervous system is norepinephrine, which is taken up by the transporter from circulation and stored in neuronal vesicles by vesicular monoamine transporter. Several radiolabelled analogs of noreponephrine have been developed, including PET tracers such as radiolabelled catecholamine analogues: $6-{ }^{18} \mathrm{~F}$-fluorodopamine, (-)-6- ${ }^{-18} \mathrm{~F}$-fluoroepinephrine, and $(-)-{ }^{11} \mathrm{C}$-epinephrine and catecholamie analogues such as ${ }^{11} \mathrm{C}$-meta-hydroxyephedrine, ${ }^{18} \mathrm{~F}$-fluorometaraminol and ${ }^{11} \mathrm{C}$-phenylephrine $[4,17]$. However, the

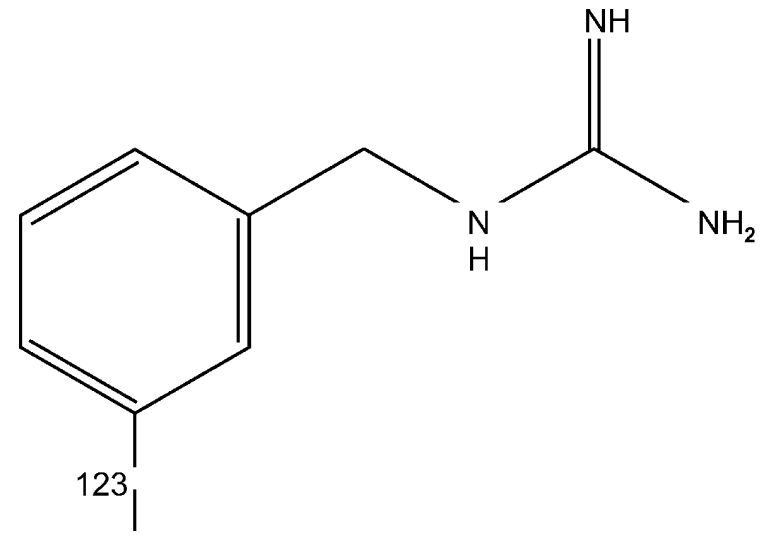

Figure 6. Structure of ${ }^{123}$-MIBG (1-(3-[123]]iodobenzyl)guanidine)

most widely used tracer is ${ }^{123}$-labelled meta-iodobenzylguanidine (123/-MIBG) [27].

\section{lobenguane $\left({ }^{123} \mathrm{I}\right)$ injection}

USP [10], Ph. Eur. [11] (monograph 1113). 1-(3-[123]]iodobenzyl)guanidine (123|-MIBG, ${ }^{123}$-lobenguane; Figure 6) shares the cellular transport and storage mechanism with norepinephrine. Both enter the neuronal cells and are stored in chromaffin granules and secreted in response to acetylcholine. ${ }^{123}$ I-MIBG is rapidly taken up by sympathetic nerves. A profound loss of ${ }^{123}$-MIBG uptake is observed in affected myocardium, similar loss of uptake was observed in patients with heart transplants [4].

\section{Future trends}

\section{Radionuclide imaging of angiogenesis}

Angiogenesis is defined as the process of sprouting new capillaries from preexisting microvessels. The main targets of imaging have been $\alpha v \beta 3$ integrin and vascular endothelial growth factor (VEGF). Arginine-glycine-aspartate (RGD) is a peptide sequence that binds integrin, and the derivatives labeled with ${ }^{18} \mathrm{~F}[28,29]$ and ${ }^{64} \mathrm{Cu}[30]$ have been evaluated in patients with cancer. An antibody which binds to VEGF has been labeled with ${ }^{124}$ [31].

${ }^{64} \mathrm{Cu}-6 \mathrm{DOTA}$-VEGF ${ }_{121}$ - a PET tracer has been also developed for imaging angiogenesis [32].

\section{Radionuclide imaging in apoptosis and necrosis}

Apoptosis is an indicator of variety of conditions within the heart, including ischemia/reperfusion injury, autoimmune myocarditis, areas at risk following acute myocardial infarction, and in transplant rejection. The protein annexin $\mathrm{V}$, which binds to phosphatidyl choline externalized by cells undergoing apoptosis, has been labeled with

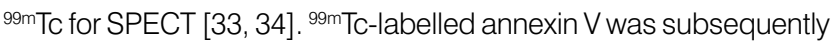
utilized in humans to detect in vivo cell death in patients presenting with myocardial infarction. Regional retention of ${ }^{99 \mathrm{~m} T c-l a b e l l e d ~ a n-~}$ nexin $V$ correlated with the perfusion defect identified 6-8 weeks after discharge, providing a proof of concept that annexin- $\mathrm{V}$ imaging can be utilized for noninvasive detection of myocardial cell death. Annexin $\mathrm{V}$ has been labeled with ${ }^{18} \mathrm{~F}$ [35], ${ }^{124}$ [36] and ${ }^{68} \mathrm{Ga}$ [37] for PET imaging. Recently, the first-in-humans study with ${ }^{18} \mathrm{~F}$-labelled 2-(5-fluoropentyl)-2-methyl malonic acid ( $\left.{ }^{18} \mathrm{~F}-\mathrm{ML}-10\right)$, a small-molecule PET tracer for apoptosis, has been also reported [38]. 
Table 2. Summary of cardiac imaging tracers

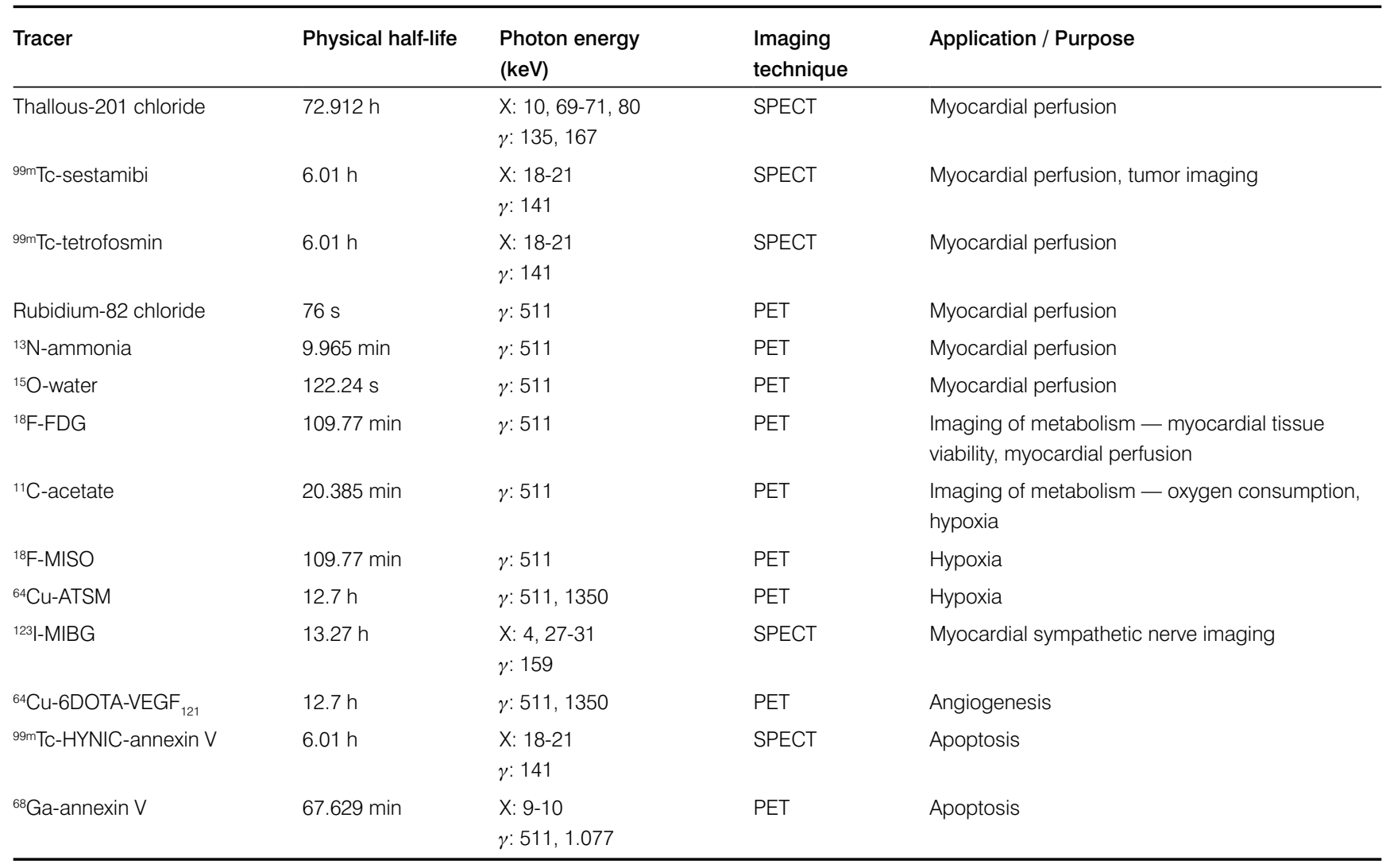

\section{Summary}

Although the myocardial perfusion studies have a well established role in the management of cardiac disorders, still the numbers of radiopharmaceuticals are under development for a variety of specific cardiac indications and their eventual clinical role remains to be seen. Table 2 provides the summary of cardiac imaging tracers in use and also at advanced stage of development, including their physical half-life, photon energy and possible applications in cardiac imaging.

Molecular imaging is a new and evolving field that employs a targeted approach to noninvasively assess biologic processes in vivo [39]. Some of the receptor targeting tracers have been described in this review. Other myocardial receptors are explored as potential targets for radionuclide imaging, such as $\alpha$-and $\beta$-adrenergic receptors, muscarinic or benzodiazepine receptors. A noninvasive imaging technique to assess the receptor density and drugs binding to these receptors would provide new insights into the etiology of myocardial disease.

\section{References}

1. DRAXIS Names GE Helathcare as Exclusive Distributor of DRAXIMAGE ${ }^{\circledR}$ sestamibi in USA. Available at: http://salesandmarketingnetwork.com/news_release. php?pipe $=0000$ ac $177000191 \& \mathrm{ID}=2022417$ \&ckey=radiopharmaceutical.

2. Królicki L, Teresińska A. The situation of nuclear medicine in Poland. The opening lecture at XII Symposium of Polish Society of Nuclear Medicine. Wrocław, 8-11 September 2010.
3. Baggish AL, Boucher ChA. Radiopharmaceutical agents for myocardial perfusion imaging. Circulation 2008; 118: 1668-1674.

4. Hwang DR, Bergman SR. Radiopharmaceuticals for Studying the heart. In: Welch MJ, Redvanly CS. Handbook of radiopharmaceuticals. Chapter 18. John Wiley \& Sons, Itd, 2003.

5. Maddahi J, Schelbert H, Brunken R, di Carli M. Role of Thallium-201 and PET imaging in evaluation of myocardial viability and management of patients with coronary artery disease and left ventricular dysfunction. J Nucl Med 1994; 35: 707-715.

6. Jain D. Technetium-99m labeled myocardial perfusion imaging agents. Semin Nucl Med 1999; 29: 221-236.

7. Sachdev SS, Ramamoorthy N, Nayak UN et al. Preparation and evaluation of 99mTc-t-butylisonitrile (99mTc-TBI) for myocardial imaging: a kit for hospital radiopharmacy. Int J Rad Appl Instrum B, 1990; 17: 543-552.

8. Kelly DP, Forster AM, Higley B et al. Technetium-99m tetrofosmin as a new radiopharmaceutical for myocardial perfusion imaging. $\mathrm{J} \mathrm{Nucl}$ Med 1993; 34: 222-227.

9. Schwaiger M, Melin J. Cardiological applications of nuclear medicine. Nuclear Medicine Sextet. The Lancet 1999; 354: 661-666.

10. The United States Pharmacopeia. USP34-NF29 2011. The United States Pharmacopeial Convention.

11. The European Pharmacopoeia 7th Edition. The European Directorate for the Quality of Medicines \& HealthCare (Council of Europe). Copyright 2010-2011.

12. GA Beller, Zaret BL. Contributions of nuclear cardiology to diagnosis and prognosis of patients with coronary artery disease. Circulation 2000; 101: 1465-1478.

13. Strauss HW, Bailey D. Resurrection of Thallium-201 for myocardial perfusion imaging. J Am Coll Cardiol Img 2009; 2: 283-285. 
14. Krause RS, Koenig BO. Review of cardiac tests. Medscape Reference available at http://emedicine.medscape.com/article/811577-overview \#aw2aab6b4

15. Myoview package insert. Arlington Heights, IL: GE Healthcare, Aug 2006.

16. Higley B, Smith FW, Smith T et al. Technetium-99m-1,2-[bis(2-ethoxyethyl)phosphino]-ethane: human biodistribution, dosimetry and safety of a new myocardial perfusion imaging agent. J Nucl Med 1993; 34: 30-38.

17. Ballinger JR. PET radiopharmaceuticals in nuclear cardiology: current status and limitations. Movahed A, Gnanasegaran G, Buscombe J, Hall M (eds). Integrating cardiology for nuclear medicine physicians. A Guide to Nuclear Medicine Physicians. Springer-Verlag, Berlin Heidelberg 2009, Chapter 32: 379-385.

18. CardioGen-82 Rubidium Rb 82 Generator product monograph. Bracco Diagnostics Inc., Princeton NJ.

19. Alvarez-Diez TM, deKemp R, Beanlands R, Vincent J. Manufacture of strontium-82/rubidium-82 generators and quality control of rubidium-82 chloride for myocardial perfusion imaging in patients using positron emission tomography. Appl Radiat Isot 1999; 50: 1015-1023.

20. Gould KL, Goldstein RA, Mullani NA et al. Noninvasive assessment of coronary stenoses by myocardial perfusion imaging during pharmacologic coronary vasodilation. VIII. Clinical feasibility of positron cardiac imaging without a cyclotron using generator-produced rubidium-82. J Am Coll Cardiol 1986; 7: 775-789.

21. Marcassa C. Rubidium-82 in Cardiological PET. OP288 in CTE 3. EANM, October 15-19, 2011, Birmingham, UK, available at: http:// //eanm11.eanm.org/abstracts/abstract_detail.php?abstractld=OP28 $8 \&$ referer $=$ session_detail.php\&navld $=65$.

22. Sinusas AJ. The potential for myocardial imaging with hypoxia markers. Semin Nucl Med 1999; 29: 330-338.

23. Chapman JD, Baer K, Lee J. Characteristics of the metabolism-induced binding of misonidazole to hypoxic mammalian cells. Cancer Research 1983; 43: 1523-1528

24. Bourgeois M, Rajerison H, Guerard F et al. Contribution of [64Cu]-ATSM PET in molecular imaging of tumor hypoxia compared to classical [18F]-MISO — a selected review. Nucl Med Rev 2011; 14: 90-95.

25. Fujibayashi Y, Taniuchi H, Yonekura Y, Ohtani H, Konishi, A. Yokoyama. Copper-62-ATSM: a new hypoxia imaging agent with high membrane permeability and low redox potential. J Nucl Med, 1997; 38: 1155-1160.

26. Hamacher K, Coenen HH, Stocklin G. Efficient stereospecific synthesis of no-carrier added 2-[18F]-fluoro-2-deoxy-D-glucose using aminopolyether supported nucleophilic substitution. J Nucl Med 1986; 27: 235-238.

27. Wieland DM, Brown L, Rogers $W$ et al. Myocardial imaging with a radioiodinated norerpinephrine storage analog. J Nucl Med 1981; 22: 22-31.

28. Haubner R, Weber WA, Beer AJ et al. Noninvasive Visualization of the Activated av 3 Integrin in Cancer Patients by Positron Emission Tomography and [18F]Galacto-RGD. PLoS Medicine http://www. plosmedicine.org 2005; 2: 244-252.

29. Haubner R, Wester HJ, Burkhart F et al. Glycosylated RGD-containing peptides: tracer for tumor targeting and angiogenesis imaging with improved biokinetics. J Nucl Med 2001; 42: 326-336.

30. Chen X, Hou Y, Tohme M et al. Pegylated Arg-Gly-Asp peptide: 64Cu labeling and PET imaging of brain tumor alphavbeta3-integrin expression. J Nucl Med 2004; 45: 1776-1783.

31. Collingridge DR, Carroll VA, Glaser M et al. The development of [(124) I] iodinated-VG76e: a novel tracer for imaging vascular endothelial growth factor in vivo using positron emission tomography. Cancer Res 2002; 62: 5912-5919.

32. Rodriguez-Porcel M, Cai W, Gheysens $\mathrm{O}$ et al. Imaging of VEGF receptor in a rat myocardial infarction model using PET. J Nucl Med, 2008; 49: 667-673

33. Hofstra L, Liem IH, Dumont EA et al. Visualisation of cell death in vivo in patients with acute myocardial infarction. Lancet 2000; 356: 209-212.

34. De Saint-Hubert M, Mottaghy FM, Vunckx K et al. Site-specific labeling of 'second generation' annexin $\vee$ with 99mTc(CO)3 for improved imaging of apoptosis in vivo. Bioorg Med Chem 2010; 18: 1356-1363.

35. S. Zijlstra, J. Gunawan, W. Burchert. Synthesis and evaluation of a 18F-labelled recombinant annaxin- $\mathrm{V}$ derivative, for identification and quantification of apoptotic cells with PET. Appl Radiat Isot 2003; 58: 201-207.

36. Glaser M, Collingridge DR, Aboyage EO et al. Luthra. lodine-124 labelled Annexin-V as a potential radiotracer to study apoptosis using positron emission tomography. Appl Radiat Isot, 2003; 58: 55-56.

37. Bauwens M, De Saint-Hubert M, Devos E et al. Site-specific 68Ga-labeled Annexin A5 as a PET imaging agent for apoptosis. Nucl Med Biol 2011; 38: 381-392

38. Hoglund J, Shirvan A, Antoni G et al. 18F-ML-10, a PET Tracer for Apoptosis: first Human Study. J Nucl Med 2011; 52: 720-725.

39. Morrison AR, Sinusas AJ. Advances in radionuclide molecular imaging of myocardial biology. J Nucl Cardiol 2010; 17: 116-134. 